\title{
Different training responses to eccentric endurance exercise at low and moderate altitudes in pre-diabetic men: a pilot study
}

\author{
Kultida Klarod $^{1,2} \cdot$ Marc Philippe $^{1,3} \cdot$ Hannes Gatterer $^{1} \cdot$ Martin Burtscher $^{1}$
}

Received: 28 April 2017/ Accepted: 11 August 2017/Published online: 23 August 2017

(c) The Author(s) 2017. This article is an open access publication

\begin{abstract}
This pilot study aimed (a) to evaluate the effects of eccentric exercise training at low and moderate altitudes on physical fitness in pre-diabetic men and (b) to establish whether or not oxidative stress levels and antioxidant status were associated with performance improvements. In this crossover trial, five pre-diabetic men conducted nine downhill walking sessions ( 3 days/week, 3 consecutive weeks) at low altitude (from 1360 to $850 \mathrm{~m}$ ) and one year later at moderate altitude (from 2447 to $2000 \mathrm{~m}$ ). Exercise testing and the determination of parameters of oxidative stress and antioxidant capacity were performed pre- and post-training. The biological antioxidant activity of plasma (BAP) increased after eccentric training at moderate altitude $(p<0.001)$, whereas diacron reactive oxygen metabolites (dROMs) remained unchanged. Also, the BAP/ dROMs ratio increased only after training at moderatealtitude training $(p=0.009)$. Maximum power output improved after training at low altitude and the changes were significantly related to baseline $\mathrm{BAP} / \mathrm{dROMs}$ ratio $(r=0.90)$. No decrease was seen for fasting plasma glucose. Eccentric exercise training in pre-diabetic men improved performance only when performed at low altitude and this improvement was positively related to the
\end{abstract}

Kultida Klarod and Marc Philippe contributed equally to the paper.

Martin Burtscher

Martin.Burtscher@uibk.ac.at

1 Department of Sport Science, Medical Section, University of Innsbruck, 6020 Innsbruck, Austria

2 Department of Physical Therapy, Faculty of Allied Health Sciences, Burapha University, Chonburi 20131, Thailand

3 Department of Sports Medicine, Institute of Sports Sciences, Justus-Liebig-University, 35394 Giessen, Germany baseline $\mathrm{BAP} / \mathrm{dROMs}$ ratio. In contrast, 3 weeks of eccentric exercise training increased BAP levels and the $\mathrm{BAP} / \mathrm{dROMs}$ ratio only at moderate altitude without improving the performance. Thus, one might speculate that the $\mathrm{BAP} / \mathrm{dROMs}$ ratio has to increase before performance improvements occur at moderate altitude.

Keywords Diabetes - Downhill walking - Oxidative stress $\cdot$ Antioxidants

\section{Introduction}

Diabetes mellitus type II is a major public health problem with more than 25 million people in Europe affected by the disease [1]. The disorder results from interactions between genetic, environmental and behavioral factors [2-4]. The latter may be considered a modifiable risk factor and mainly denotes poor health behavior in terms of a high caloric diet and physical inactivity. In view of that, it has been persistently shown that reducing caloric intake and being physically active or performing endurance and strength training on a regular basis to improve physical fitness prevent diabetes mellitus type II development [5] and ameliorate glycemic control [6-8].

Unaccustomed eccentric exercise (muscle lengthening contraction form) is associated with muscle damage inducing reduced glucose transporter type 4 (GLUT4) levels that seems to be the major reason for transient insulin resistance [9-11]. However, it has been shown that repeated bouts of eccentric exercise are protective against further damage caused by subsequent eccentric sessions $[12,13]$. Furthermore, it was recently reported that eccentric exercise is not only an effective training method to increase muscle strength and endurance, but may also 
increase glucose tolerance comparable to concentric exercise [14-20]. Eccentric endurance exercise might be implemented by downhill walking/hiking in a hilly or mountainous environment. In contrast to uphill walking which is considered a concentric endurance exercise, downhill walking opposes less strain on the cardiovascular system but a relatively high strain on the contractile units of muscles [21, 22]. Therefore, downhill walking might be a valuable training modality for persons displaying a low physical fitness and impaired glucose metabolism, as for example subjects suffering from pre-diabetes.

Besides the possibility of mountainous environments to easily perform eccentric endurance exercises, increasing altitude also involves decreasing atmospheric pressure leading to hypobaric hypoxia. While altitudes above $1500 \mathrm{~m}$ lead to an altitude-dependent decline of exercise capacity [23, 24], hypoxia has been shown to improve glucose transport and insulin action [25-27] and furthermore may be a stimulus for increasing exercise performance [28]. In this regard, research has shown that both eccentric exercise and hypoxia may induce inflammation and increase reactive oxygen species (ROS) [29-33]. High levels of contraction-induced ROS have been associated with muscle damage and impaired muscle function [34] and acute exercise under hypoxic conditions promotes DNA strand breaks and oxidative DNA damage more than exercise under normoxia [35]. However, contraction-induced ROS also activates important cell signaling pathways mediating training adaptations such as improved antioxidant capacity [36], mitochondrial biogenesis [37-39] and hypertrophy [40]. In fact, it was demonstrated that positive exercise-induced adaptations such as vasodilation [41], mitochondrial biogenesis [39, 42] and insulin sensitivity [43] are blunted when loading cells with high doses of antioxidants or after oral antioxidant treatment. Moreover, exercise-induced ROS production is highly individual and persons producing less exercise-induced oxidative stress exhibited the lowest training adaptations after endurance training [44-46]. It is also known that overweight persons with type II diabetes display higher basal levels of oxidative stress that can be reduced by exercise training, but the link between reduction of basal oxidative stress and improved glucose metabolism has not yet been confirmed [47, 48]. Additionally, eccentric exercise was reported to increase the antioxidative capacity and thus to be protective against oxidative injury [49]. Thus, we assumed that eccentric endurance training performed at low or moderate altitude (i.e., 2000-2500 m) might have distinct effects on redox status and could differently impact on physical fitness.

The effects of eccentric exercise training at moderate altitude on exercise performance and redox status in prediabetic people are not established yet. Therefore, this study aimed (a) to evaluate the effects of eccentric exercise training at low and moderate altitudes on physical fitness in pre-diabetic men and (b) to establish whether or not oxidative stress levels and antioxidant status are associated with performance improvements. We hypothesized that eccentric exercise training performed at moderate altitude will improve performance more than at low altitude and that redox changes may at least partly explain the expected differences.

\section{Methods}

\section{Participants}

Five pre-diabetic men (age $56.8 \pm 5.8$ years; weight $83.8 \pm 10.7 \mathrm{~kg}$; height $173.8 \pm 3.1 \mathrm{~cm}$ ) gave their written informed consent to participate in the study. Pre-diabetes was defined according to the American Diabetes Association [50] and included participants with impaired fasting glucose and/or impaired glucose tolerance. Impaired fasting glucose was defined as fasting plasma glucose levels $\geq 100$ and $<126 \mathrm{mg} / \mathrm{dl}$, and impaired glucose tolerance was defined as 2-h plasma glucose values in the oral glucose tolerance test of $\geq 140$ and $<200 \mathrm{mg} / \mathrm{dl}$. Exclusion criteria were any kind of acute or chronic diseases, smoking and body mass index $>30 \mathrm{~kg} / \mathrm{m}^{2}$ or musculoskeletal problems not compatible with the used downhill walking exercises. The baseline characteristics of the study participants are shown in Table 1 . The study was carried out in accordance with the ethical standards laid down in the Declaration of Helsinki and the protocol was approved by the ethics committee of the Medical University of Innsbruck (Protocol ID: AN5029; ClinicalTrials.gov ID: NCT01890876).

\section{Procedures}

The present study is a follow-up of an initial project which was designed as an investigator-initiated two-group random selection pre-test post-test trial. In that trial, we investigated the effects of 3 weeks of uphill and downhill walking at low altitude on fat and glucose metabolism in pre-diabetic men [51]. The eccentric walking protocol has been repeated 1 year later at moderate altitude. Primarily, based on the results of Smutok et al. [52], we calculated a sample size of at least eight participants for the initial project (G*Power, Version 3.1.5). However, of the eight subjects participating in downhill walking in the first year, only five agreed to repeat the downhill walking program at moderate altitude. The low and the moderate altitude training periods were accomplished 1 year apart with the low-altitude training trial performed first. The methodological approach was the same for both periods. Each 
Table 1 Baseline characteristics of the participants under normoxic (low altitude) and hypoxic (moderate altitude) conditions

\begin{tabular}{lccc}
\hline Parameters & Normoxia $(N=5)$ & Hypoxia $(N=5)$ & $p$ values \\
\hline Weight $(\mathrm{kg})$ & $83.8 \pm 10.7$ & $83.5 \pm 8.5$ & 0.735 \\
$\mathrm{BMI}\left(\mathrm{kg} / \mathrm{m}^{2}\right)$ & $27.8 \pm 3.5$ & $27.6 \pm 3.5$ & 0.795 \\
$P_{\max }(\mathrm{W})$ & $161.2 \pm 47.6$ & $188.2 \pm 47.1$ & 0.007 \\
$\mathrm{Hf}$ & $151.4 \pm 13.8$ & 0.260 \\
Fasting plasma glucose $(\mathrm{mg} / \mathrm{dl})$ & $127.4 \pm 39.8$ & $116.4 \pm 22.7$ & 0.371 \\
$\mathrm{VO}_{2 \max }$ rel. $(\mathrm{ml} / \mathrm{min} / \mathrm{kg})$ & $31.5 \pm 10.6$ & $32.3 \pm 9.3$ & 0.405 \\
\hline
\end{tabular}

Values are mean $\pm \mathrm{SD}$

$H f_{\max }$ maximum heart rate reached during maximum exercise capacity testing, $P_{\max }$ maximum power output reached during maximum exercise capacity testing, $V_{2} O_{2 \max } \mathrm{rel}$. relative maximum oxygen uptake achieved during exercise capacity testing testing and training period included two pre-test days, nine downhill (eccentric exercise) walking sessions and two post-test days. During the first pre-test, fasting venous blood samples were collected and the participants underwent a routine medical examination and anthropometric measurements. On the second day, the participants performed a symptom-limited incremental exercise test (cycle ergometer test). One week after the pre-tests, the downhill walking training period started. The nine walking sessions were performed on Mondays, Wednesdays and Fridays on three consecutive weeks. The participants were asked to walk as fast as possible or at a maximum intensity corresponding to an individual RPE of 15 [53]. Participants were not allowed to run. The starting point for the low-altitude training period was at an altitude level of $1360 \mathrm{~m}$ above sea level and the finish point was at an altitude level of $850 \mathrm{~m}$ above sea level. The path had a relatively continuous slope of $10.2 \%$ and a length of $5000 \mathrm{~m}$. The mean walking time per session was $69.3 \pm 5.1 \mathrm{~min}$. The starting point for the moderate altitude walking sessions was at an altitude level of $2447 \mathrm{~m}$ above sea level and the end point was at an altitude level of $2000 \mathrm{~m}$ above sea level. The path had a relatively continuous slope of $9.7 \%$ with a length of $4600 \mathrm{~m}$. The mean walking time per session was $57.0 \pm 3.8$ min. During both training periods participants were brought to the starting point by car or cable car. Exercise testing after the training program was conducted on the same day as the last walking session. Fasting blood sampling and anthropometric testing took place 1-2 days after the last walking session.

\section{Measurements during walking}

The heart rate and walking time of each participant were monitored and stored for every walking session by a Polar watch (RS800CX, Polar Electro OY, Kempele, Finland). The average rate of perceived exertion was noted after each walking session. At the beginning of each walking session, delayed onset muscle soreness (DOMS) of the previous walking session was assessed. A graded scale for muscle pain and muscle soreness ranging from 1 to 10 (1 meaning no pain/soreness and 10 meaning maximal pain/soreness) was used similarly as done by Coratella and Bertinato [54].

\section{Exercise testing}

Exercise capacity was assessed by a symptom-limited cycle ergometer test (Excalibur Sport, Lode, The Netherlands). We expected a peak performance of our study participants between 150 and $200 \mathrm{~W}$. Since the recommended duration for incremental exercise tests to exhaustion is generally between 8 and $12 \mathrm{~min}$, we decided to start with an initial load of $50 \mathrm{~W}$ for 3 min followed by $50 \mathrm{~W}$ increments every $3 \mathrm{~min}$ up to exhaustion, resulting in a total test duration of 9-12 min. During the test, gas analyses were performed (Oxycon Alpha, Jaeger, Germany) and the participants were continuously monitored by ECG (Schiller AT-10, Austria). The main outcome parameters were the maximum heart rate, maximum power output and the maximum relative oxygen uptake.

\section{Fasting plasma glucose}

Fasting venous blood samples were taken to quantify fasting plasma glucose using a commercially available enzymatic kit (Roche Diagnostic Systems, Basel, Switzerland) on a Hitachi 902 Autoanalyser (Roche Diagnostic Systems, Basel, Switzerland) at the laboratory of the Medical University of Innsbruck.

\section{Oxidative stress and antioxidant status markers}

Hydroperoxides were measured by the plasma levels of diacron reactive oxygen metabolites (dROMs) using the Free Carpe Diem device (FREE ${ }^{\circledR}$ Carpe Diem; Diacron International, Italy). dROMs levels of plasma in the presence of iron can develop alkoxyl and peroxyl radicals. The radicals can oxidize an alkyl-substituted aromatic amine, 
thus converting them into a pink-colored derivative. It can be detected by a spectrophotometer at $546 \mathrm{~nm}$. The results are expressed in arbitrary units, namely Carratelli units (U.CARR). A single U.CARR corresponds to $0.08 \mathrm{ng} /$ $100 \mathrm{ml}$ of $\mathrm{H}_{2} \mathrm{O}_{2}$ [55].

The biological antioxidant activity of plasma (BAP) was determined using the Free Carpe Diem device (FREE $^{\circledR}$ Carpe Diem; Diacron International, Italy). The test is based on a colored solution containing ferric $\mathrm{Fe}^{3+}$ ions bound to a chromogenic substrate which is decolorized on reduction of $\mathrm{Fe}^{3+}$ to $\mathrm{Fe}^{2+}$ ions by a reducing power of the antioxidant activity of plasma added to the reaction solution. This reaction can measure photometrically the intensity of decoloration at wavelength $505 \mathrm{~nm}$. The normal value for BAP in healthy subjects is $>2200 \mu \mathrm{mol} / \mathrm{l}[55]$.

\section{Statistical analysis}

Data analyses were performed using SPSS version 18.0 (SPSS Inc., Chicago, IL, USA). All values are presented as mean \pm SD. Low- vs. moderate-altitude training session parameters were evaluated with the use of the Wilcoxon test. Differences between low- and moderate-altitude training outcomes of BAP, dROMs, fasting plasma glucose, maximum power output, maximum heart rate and body mass index were calculated by using two-factor [condition: normoxia (low altitude) vs. hypoxia (moderate altitude) and time: pre- vs. post-training] repeated-measures analysis of variance (ANOVA). Bivariate correlation analyses were performed using Pearson or Spearman's rank correlation as appropriate. A $p$ value $\leq 0.05$ was considered statistically significant.

\section{Results}

\section{Walking session results}

The results of the parameters assessed during walking are presented in Table 2. The mean walking time was significantly lower for moderate-altitude walking compared to low-altitude walking. No other training parameters differed significantly between the two training regimens. Downhill walking at moderate altitude caused no subjective DOMS, while downhill walking at low altitude caused a rather negligible amount of subjective DOMS.

\section{Oxidative stress and antioxidant parameters}

Table 3 shows the outcomes of the oxidative stress and antioxidative defense parameters. dROMs levels were neither affected by training (time effect, $p>0.05$ ) nor by altitude condition (interaction effect, $p>0.05$ ). On the contrary, BAP changed over time with an interaction effect (time $\times$ altitude level, $p<0.05$ ). Post hoc analyses revealed that BAP levels increased only after eccentric training at moderate altitude $(p<0.001)$. The BAP/dROMs ratio indicating redox balance increased also after training at moderate-altitude training $(p=0.009$, Fig. 1$)$, but was unaffected at low altitude.

\section{Anthropometric, performance and metabolic data}

Table 4 shows the outcomes of the anthropometric, performance and metabolic data. Training and altitude level did not affect body mass index, maximum heart rate and fasting plasma glucose ( $p>0.05$ no time or interaction effects). On the contrary, a significant interaction effect (time $\times$ altitude condition) was found for maximum power output which only improved after training at low, but not at moderate altitude.

\section{Correlations}

Correlation analyses revealed that the pre-training BAP/ dROMs ratio was significantly related to changes in maximum power output after the low-altitude training period ( $r=0.90, p=0.037$, Fig. 2), but not after the moderatealtitude training period $(r=0.30, p=0.624)$.

\section{Discussion}

The main findings of the present study were (a) that 3 weeks of eccentric exercise in pre-diabetic men at moderate altitude (hypoxia), in contrast to low altitude
Table 2 Results of the nine downhill walking sessions under normoxic (low altitude) and hypoxic (moderate altitude) conditions

\begin{tabular}{lccc}
\hline & Normoxia $(N=5)$ & Hypoxia $(N=5)$ & $p$ values \\
\hline Mean walking time pws (s) & $4159(304)$ & $3421(227)$ & $0.043^{*}$ \\
$\mathrm{Hf}_{\text {mean }}(\mathrm{bpm})$ & $93.2(9.8)$ & $98.4(5.7)$ & 0.138 \\
$\mathrm{RPE}_{\text {mean }}[6-20]$ & $8.9(1.1)$ & $8.5(0.4)$ & 0.273 \\
Pain mean [1-10] & $1.1(0.1)$ & $1.0(0.0)$ & 0.180 \\
Soreness mean [1-10] & $1.2(0.2)$ & $1.0(0.0)$ & 0.109 \\
\hline
\end{tabular}

Values are as mean $\pm \mathrm{SD}$

$p w s$ per walking session, $H f_{\text {mean }}$ mean heart frequency, $R P E_{\text {mean }}$ mean rate of perceived exertion $* p \leq 0.05$ 
Table 3 Pre- and post-training levels of dROMs and BAP under normoxic (low altitude) and hypoxic (moderate altitude) conditions

\begin{tabular}{|c|c|c|c|c|c|c|}
\hline & \multicolumn{2}{|c|}{ Pre-training (mean $\pm \mathrm{SD}$ ) } & \multicolumn{2}{|c|}{ Post-training (mean $\pm \mathrm{SD}$ ) } & \multirow{2}{*}{$\begin{array}{l}\text { Main effect time } \\
(p \text { values })\end{array}$} & \multirow{2}{*}{$\begin{array}{l}\text { Interaction time } \times \text { condition } \\
(p \text { values })\end{array}$} \\
\hline & Normoxia & Hypoxia & Normoxia & Hypoxia & & \\
\hline $\begin{array}{l}\text { dROMs } \\
\text { (UCARR) }\end{array}$ & $234.8 \pm 38.7$ & $231.4 \pm 31.1$ & $173.8 \pm 34.0$ & $231.6 \pm 40.8$ & 0.103 & 0.171 \\
\hline $\mathrm{BAP}(\mu \mathrm{mol} / \mathrm{l})$ & $1575.6 \pm 301.1$ & $1241.2 \pm 142.8$ & $1460.5 \pm 73.2$ & $2279.5 \pm 202.0$ & $<0.001 *$ & $0.006 *$ \\
\hline
\end{tabular}

$d R O M s$ the diacron reactive oxygen metabolites, $B A P$ the biological antioxidant activity of plasma

$* p \leq 0.05$

Fig. 1 Ratio of BAP/dROMs levels at pre-training and posttraining in normoxia and hypoxia groups

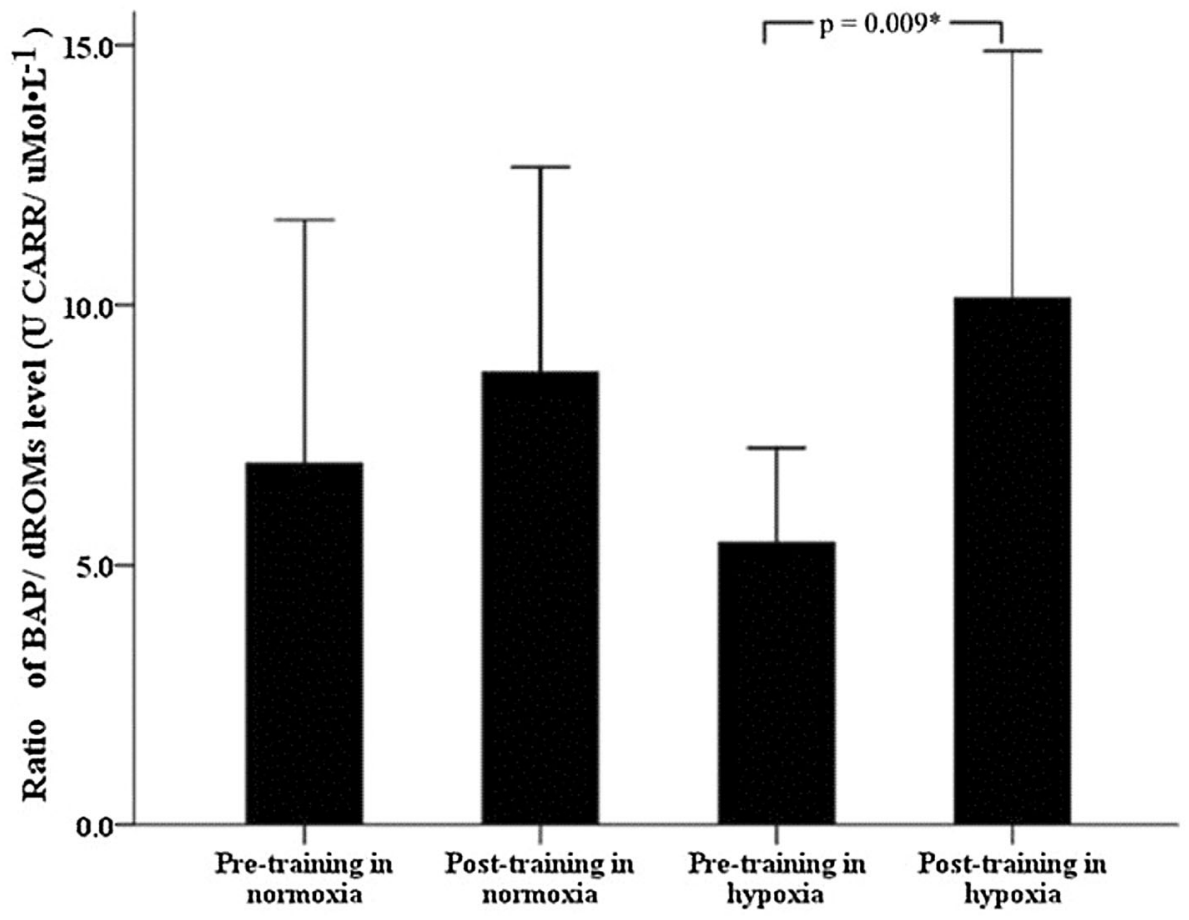

Table 4 Changes of anthropometric, exercise capacity and metabolic parameters under normoxic (low altitude) and hypoxic (moderate altitude) conditions

\begin{tabular}{|c|c|c|c|c|}
\hline & \multicolumn{2}{|c|}{ Mean differences post minus pre \pm SD } & \multirow{2}{*}{$\begin{array}{l}\text { Main effect time } \\
\text { ( } p \text { values) }\end{array}$} & \multirow{2}{*}{$\begin{array}{l}\text { Interaction time } \times \text { condition } \\
(p \text { values })\end{array}$} \\
\hline & Normoxia & Hypoxia & & \\
\hline$\Delta \mathrm{BMI}\left(\mathrm{kg} / \mathrm{m}^{2}\right)$ & $-0.05 \pm 0.36$ & $0.12 \pm 0.37$ & 0.829 & 0.231 \\
\hline$\Delta \mathrm{Hf}_{\max }(\mathrm{bpm})$ & $2.20 \pm 10.11$ & $7.00 \pm 9.35$ & 0.226 & 0.460 \\
\hline$\Delta P_{\max }(\mathrm{W})$ & $9.00 \pm 8.00$ & $-2.00 \pm 10.84$ & 0.436 & $0.015^{*}$ \\
\hline$\Delta$ Fasting plasma glucose $(\mathrm{mg} / \mathrm{dl})$ & $-14.40 \pm 29.68$ & $5.00 \pm 5.00$ & 0.563 & 0.176 \\
\hline
\end{tabular}

$H f_{\max }$ maximum heart rate reached during maximum exercise capacity testing, $P_{\max }$ maximum power output reached during maximum exercise capacity testing

$* p \leq 0.05$

(normoxia), resulted in a significant increase in BAP and BAP/dROMs ratio, but did not improve performance and (b) that the BAP/dROMs ratio was positively correlated with performance increase at low altitude. No training- dependent changes in fasting plasma glucose were seen after training at low or moderate altitudes.

In contrast to the present study, Pialoux et al. demonstrated that training under hypoxic condition increased 
Fig. 2 Relationship between the ratio of $\mathrm{BAP} / \mathrm{dROMs}$ level at pre-training and $\Delta$ post-pre of $P_{\max }$ in normoxia

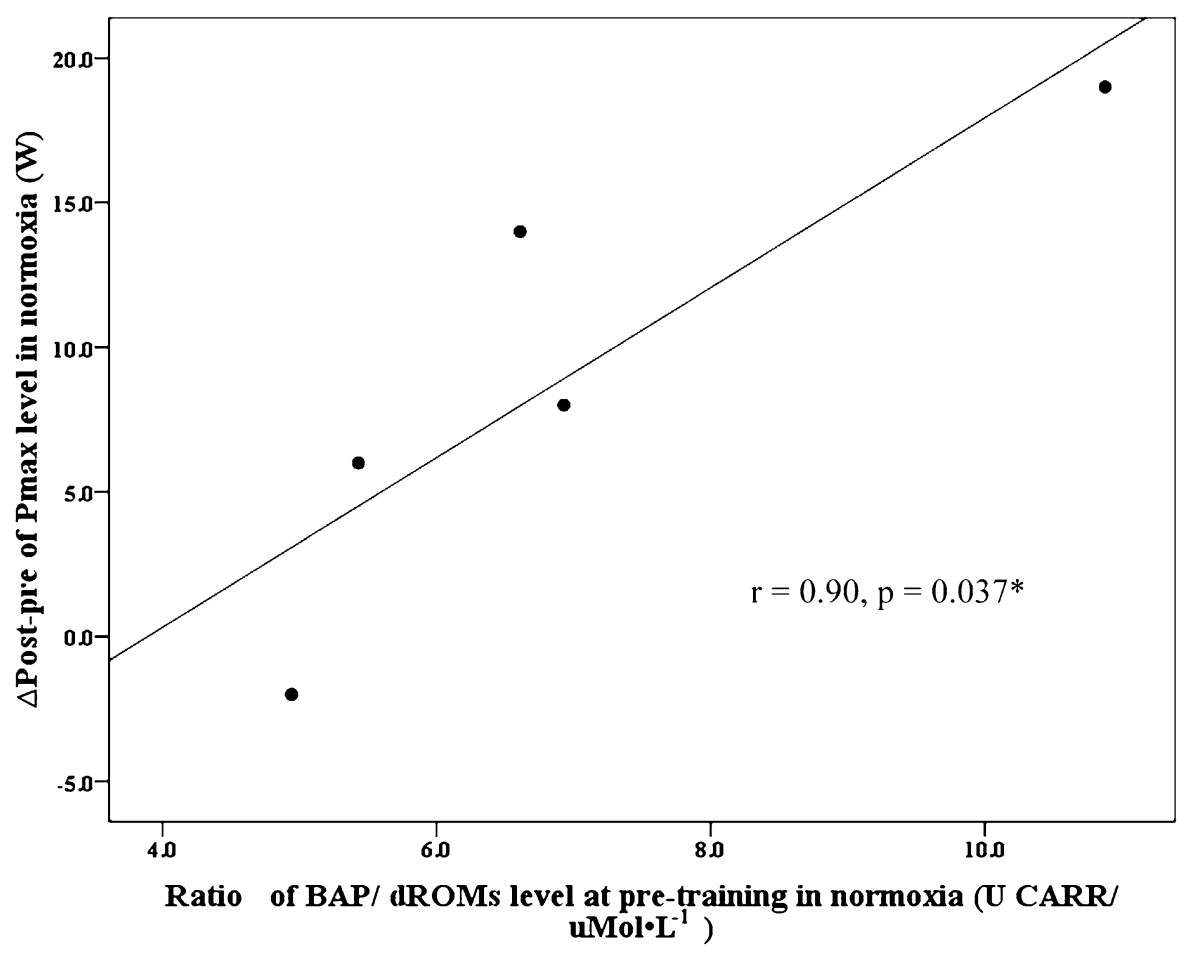

oxidative stress (plasma levels of advanced oxidation protein products and malondialdehydes) and weakened antioxidant capacities (ferric-reducing antioxidant power, alpha-tocopherol and beta-carotene) [56]. The authors proposed that the combination of intense running and hypoxia may generate a cumulative oxidative stress [56]. This discrepancy may likely be explained by different types of stressors which depend upon the type of exercise, intensity of exercise training, duration of exercise training and the type and severity of hypoxia [57]. Whereas Pialoux et al. applied intense running in hypoxia (simulated altitude of $3000 \mathrm{~m}$ ) [56], participants of our study performed downhill walking (eccentric exercise) from about 2500 to $2000 \mathrm{~m}$. Thus, the low energy demand during non-muscle damaging eccentric exercise in rather moderate hypoxia may have generated enhanced BAP levels. This enhancement of antioxidant levels without change in oxidative stress levels in the present study may be considered beneficial adaptation to exercise training in moderate hypoxia $(\sim 2000 \mathrm{~m})$ [58]. Such adaptations to chronic exercise training at low altitude have been reported repeatedly after training in general [59], in already trained people [60] and in response to increments in training volume as well [61]. Thus, antioxidant capacity may be enhanced under chronic oxidative stress conditions due to well-designed prolonged exercise training $[60,62]$. In moderate hypoxia, low-intensity eccentric exercise training may generate similar effects, but more intense training or more severe hypoxia would potentially increase oxidative stress likely requiring antioxidant supplementation [57].
It has been proposed that the adaptive changes in antioxidant efficacy may depend on the pre-training level and the duration of training $[60,63]$ and also on training loads [63]. Thus, the lack of alteration of either oxidative stress or antioxidant capacity by chronic low-intensity endurance eccentric exercise under normoxic condition in the present study might well be due to insufficiently high stressors for activation toward protective increase in antioxidants. This is in line with Margaritis et al. [63] and Dernbach et al. [64] who reported no significant changes in oxidative stress and antioxidant efficacy after low-altitude training in already well-trained people $[63,64]$. On the other hand, however, endurance eccentric exercise at low altitude was associated with improvement in exercise performance, and participants with high BAP/dROMs ratios benefited more than those with lower ratios. This observation suggests that a higher BAP/dROMs ratio might favor beneficial training effects on performance. Why this was not true under hypoxic conditions might be due to somewhat more pronounced ROS production at moderate altitude requiring even higher BAP/dROMs ratios. Thus, it would make sense to increase first the BAP as observed before performance improvement occurs.

The observation that fasting plasma glucose did not change differently between normoxic and hypoxic conditions is in accordance with previous studies [65-67], which found that fasting plasma glucose was not affected by living at moderate altitude or endurance exercise training over 3 weeks or less [65-67]. 
The exploratory research design and the small sample size of the present study are the most important limitations to be mentioned. The exploratory design has been applied because there are no studies available that compared the effects of eccentric endurance exercise in pre-diabetic men between low and moderate altitude. The small sample size is at least partly due to logistical problems of very standardized downhill walking for 3 weeks at low and moderate altitudes. Differences between the walking programs may represent further limitations. We tried to choose very similar walking paths for the low- and moderate-altitude training sessions. We managed to have comparable slope gradients, but the total distance of the two paths differed by $400 \mathrm{~m}$. Somewhat longer walking periods indicated a higher training volume at low altitude, while heart rates in contrast to RPE indicated a higher training intensity at moderate altitude. These volume and intensity differences between the two training regimens might also have affected changes of physical performance and redox status. We cannot totally rule out the presence of muscle damage during post-training tests, as we did not measure creatine kinase or other biomarkers of muscle damage. However, subjective DOMS assessment indicated no muscle damage and it also has been reported that repeated bouts of eccentric exercise are protective against further damage caused by subsequent eccentric sessions $[12,13]$. Thus, we assume that post-training measurements have not been affected by exercise-induced muscle damage. Maximum power output was somewhat higher before the training at moderate altitude which could have prevented further improvement. However, the decline in maximum power output post-training may indicate a real lack of training effect at moderate altitude. Keeping in mind that this was a crossover study design, the results regarding BAP seem convincing, but with regard to dROMs the small sample size may have led to a type II error.

\section{Conclusion and practical applications}

Eccentric endurance exercise in pre-diabetic men improved performance only when conducted at low altitude and this improvement was positively related to the baseline BAP/ dROMs ratio. In contrast, 3 weeks of eccentric exercise training increased BAP levels and the BAP/dROMs ratio only at moderate altitude without improving the performance. Thus, one might speculate that enhancement of BAP before downhill walking at moderate altitudes might favor the beneficial effects on performance. Antioxidant strategies for prophylactic use might include those providing electrons to radicals such as vitamin $\mathrm{C}$ and $\mathrm{E}$ [68]. If this is right, one might further speculate that antioxidant pre-treatment in pre-diabetic men would result in similar performance increases due to eccentric endurance exercise at moderate altitude as shown at low altitude.

If confirmed in well-controlled studies on larger samples, the presented findings might be of clinical relevance for many patients performing leisure activities in the mountainous areas of the Alps. On the one hand, patients with low exercise tolerance who are unable to walk uphill may benefit from and enjoy the physically less demanding downhill walking. Depending on the antioxidant capacity, eccentric exercise effects may be somewhat different between low and moderate altitude.

Acknowledgements Open access funding provided by University of Innsbruck and Medical University of Innsbruck. We are grateful to the University of Innsbruck for continuous support of our research work. This project was also supported by the National Research Fund, Luxembourg. We would like to thank the Lifts Kühtai GmbH and Co. KG and the TVB Kühtai for their support during the moderate-altitude training phase with special thanks to Wolfgang Suitner and Wilhem Mareiler.

\section{Compliance with ethical standards}

Conflict of interest All the authors have declared no conflict of interest.

Ethical approval All procedures performed in studies involving human participants were in accordance with the ethical standards of the institutional and/or national research committee and with the 1964 Helsinki Declaration and its later amendments or comparable ethical standards.

Informed consent All the participants gave their written informed consent to participate in the study.

Open Access This article is distributed under the terms of the Creative Commons Attribution 4.0 International License (http://crea tivecommons.org/licenses/by/4.0/), which permits unrestricted use, distribution, and reproduction in any medium, provided you give appropriate credit to the original author(s) and the source, provide a link to the Creative Commons license, and indicate if changes were made.

\section{References}

1. The Federal Ministry of Health and Women, Division IV (2006) European Union conference on prevention of type 2 diabetes, Vienna

2. O'Rahilly S (2009) Human genetics illuminates the paths to metabolic disease. Nature 462:307-314. doi:10.1038/nature08532

3. Sui X, Hooker SP, Lee IM, Church TS, Colabianchi N, Lee CD et al (2008) A prospective study of cardiorespiratory fitness and risk of type 2 diabetes in women. Diabetes Care 31:550-555. doi: $10.2337 / \mathrm{dc} 07-1870$

4. Tuomilehto J, Lindstrom J, Eriksson JG, Valle TT, Hamalainen $\mathrm{H}$, Ilanne-Parikka $\mathrm{P}$ et al (2001) Prevention of type 2 diabetes mellitus by changes in lifestyle among subjects with impaired glucose tolerance. N Engl J Med 344:1343-1350. doi:10.1056/ NEJM200105033441801

5. Lindstrom J, Ilanne-Parikka P, Peltonen M, Aunola S, Eriksson JG, Hemio K et al (2006) Sustained reduction in the incidence of 
type 2 diabetes by lifestyle intervention: follow-up of the Finnish Diabetes Prevention Study. Lancet 368:1673-1679. doi:10.1016/ S0140-6736(06)69701-8

6. Kang J, Kelley DE, Robertson RJ, Goss FL, Suminski RR, Utter AC et al (1999) Substrate utilization and glucose turnover during exercise of varying intensities in individuals with NIDDM. Med Sci Sports Exerc 31:82-89

7. Burtscher M, Gatterer H, Kunczicky H, Brandstatter E, Ulmer H (2009) Supervised exercise in patients with impaired fasting glucose: impact on exercise capacity. Clin J Sport Med 19:394-398. doi:10.1097/JSM.0b013e3181b8b6dc

8. Gatterer H, Ulmer H, Dzien A, Somavilla M, Burtscher M (2011) High cardiorespiratory fitness is more beneficial in pre-diabetic men than women. Clinics (Sao Paulo) 66:747-751

9. Asp S, Daugaard JR, Richter EA (1995) Eccentric exercise decreases glucose transporter GLUT4 protein in human skeletal muscle. J Physiol 482:705-712

10. Jensen TE, Richter EA (2012) Regulation of glucose and glycogen metabolism during and after exercise. J Physiol 590:1069-1076. doi:10.1113/jphysiol.2011.224972

11. Richter EA, Hargreaves M (2013) Exercise, GLUT4, and skeletal muscle glucose uptake. Physiol Rev 93:993-1017. doi:10.1152/ physrev.00038.2012

12. Maeo S, Ochi Y, Yamamoto M, Kanehisa H, Nosaka K (2015) Effect of a prior bout of preconditioning exercise on muscle damage from downhill walking. Appl Physiol Nutr Metab 40:274-279. doi:10.1139/apnm-2014-0390

13. Coratella G, Chemello A, Schena F (2016) Muscle damage and repeated bout effect induced by enhanced eccentric squats. J Sports Med Phys Fitness 56:1540-1546

14. Zeppetzauer M, Drexel H, Vonbank A, Rein P, Aczel S, Saely CH (2013) Eccentric endurance exercise economically improves metabolic and inflammatory risk factors. Eur J Prev Cardiol 20:577-584. doi:10.1177/2047487312444236

15. Drexel H, Saely CH, Langer P, Loruenser G, Marte T, Risch L et al (2008) Metabolic and anti-inflammatory benefits of eccentric endurance exercise-a pilot study. Eur $\mathbf{J}$ Clin Investig 38:218-226. doi:10.1111/j.1365-2362.2008.01937

16. Philippe M, Junker G, Gatterer H, Melmer A, Burtscher M (2016) Acute effects of concentric and eccentric exercise matched for energy expenditure on glucose metabolism in healthy females: a randomized crossover trial. Springerplus 5:1455. doi:10.1186/ s40064-016-3062-z

17. Philippe M, Krusmann PJ, Mersa L, Eder EM, Gatterer H, Melmer A et al (2016) Acute effects of concentric and eccentric exercise on glucose metabolism and interleukin-6 concentration in healthy males. Biol Sport 33:153-158. doi:10. $5604 / 20831862$

18. Hoppeler H (2016) Moderate load eccentric exercise; a distinct novel training modality. Front Physiol 7:483. doi:10.3389/fphys. 2016.00483

19. Wood RE, Morgan HE (1969) Regulation of sugar transport in avian erythrocytes. J Biol Chem 244:1451-1460

20. Marcus RL, Lastayo PC, Dibble LE, Hill L, McClain DA (2009) Increased strength and physical performance with eccentric training in women with impaired glucose tolerance: a pilot study. J Womens Health (Larchmt) 18:253-260. doi:10.1089/jwh.2007. 0669

21. Camillo CA, Burtin C, Hornikx M, Demeyer H, De Bent K, van Remoortel $\mathrm{H}$ et al (2015) Physiological responses during downhill walking: a new exercise modality for subjects with chronic obstructive pulmonary disease? Chron Respir Dis 12:155-164. doi:10.1177/1479972315575717

22. Johnson AT, Benjamin MB, Silverman N (2002) Oxygen consumption, heat production, and muscular efficiency during uphill and downhill walking. Appl Ergon 33:485-491
23. Fulco CS, Rock PB, Cymerman A (1998) Maximal and submaximal exercise performance at altitude. Aviat Space Environ Med 69:793-801

24. Gatterer H, Greilberger J, Philippe M, Faulhaber M, Djukic R, Burtscher M (2013) Short-term supplementation with alpha-ketoglutaric acid and 5-hydroxymethylfurfural does not prevent the hypoxia induced decrease of exercise performance despite attenuation of oxidative stress. Int J Sports Med 34:1-7. doi:10. 1055/s-0032-1312584

25. Constable SH, Favier RJ, Cartee GD, Young DA, Holloszy JO (1988) Muscle glucose transport: interactions of in vitro contractions, insulin, and exercise. J Appl Physiol 64:2329-2332

26. Cartee GD, Douen AG, Ramlal T, Klip A, Holloszy JO (1991) Stimulation of glucose transport in skeletal muscle by hypoxia. J Appl Physiol 70:1593-1600

27. Zhang JZ, Behrooz A, Ismail-Beigi F (1999) Regulation of glucose transport by hypoxia. Am J Kidney Dis 34:189-202. doi:10. 1053/AJKD03400189

28. Vogt M, Hoppeler H (2010) Is hypoxia training good for muscles and exercise performance? Prog Cardiovasc Dis 52:525-533. doi:10.1016/j.pcad.2010.02.013

29. Silva LA, Pinho CA, Silveira PC, Tuon T, De Souza CT, DalPizzol F et al (2010) Vitamin E supplementation decreases muscular and oxidative damage but not inflammatory response induced by eccentric contraction. J Physiol Sci 60:51-57. doi:10. 1007/s12576-009-0065-3

30. Silva LA, Silveira PC, Ronsani MM, Souza PS, Scheffer D, Vieira LC et al (2011) Taurine supplementation decreases oxidative stress in skeletal muscle after eccentric exercise. Cell Biochem Funct 29:43-49. doi:10.1002/cbf.1716

31. Close GL, Ashton T, Cable T, Doran D, MacLaren DP (2004) Eccentric exercise, isokinetic muscle torque and delayed onset muscle soreness: the role of reactive oxygen species. Eur J Appl Physiol 91:615-621. doi:10.1007/s00421-003-1012-2

32. Jefferson JA, Simoni J, Escudero E, Hurtado ME, Swenson ER, Wesson DE et al (2004) Increased oxidative stress following acute and chronic high altitude exposure. High Alt Med Biol 5:61-69. doi:10.1089/152702904322963690

33. Karakurum M, Shreeniwas R, Chen J, Pinsky D, Yan SD, Anderson $\mathrm{M}$ et al (1994) Hypoxic induction of interleukin-8 gene expression in human endothelial cells. J Clin Investig 93:1564-1570. doi:10.1172/JCI117135

34. Peternelj TT, Coombes JS (2011) Antioxidant supplementation during exercise training: beneficial or detrimental? Sports Med 41:1043-1069. doi:10.2165/11594400-000000000-00000

35. Moller P, Loft S, Lundby C, Olsen NV (2001) Acute hypoxia and hypoxic exercise induce DNA strand breaks and oxidative DNA damage in humans. FASEB J 15:1181-1186

36. Gomez-Cabrera MC, Domenech E, Viña J (2008) Moderate exercise is an antioxidant: upregulation of antioxidant genes by training. Free Radic Biol Med 44:126-131. doi:10.1016/j.free radbiomed.2007.02.001

37. Gomez-Cabrera MC, Viña J, Ji LL (2016) Role of redox signaling and inflammation in skeletal muscle adaptations to training. Antioxidants (Basel) 5(4):E48. doi:10.3390/antiox5040048

38. Gomez-Cabrera MC, Domenech E, Romagnoli M, Arduini A, Borras C, Pallardo FV et al (2008) Oral administration of vitamin $\mathrm{C}$ decreases muscle mitochondrial biogenesis and hampers training-induced adaptations in endurance performance. Am J Clin Nutr 87:142-149

39. Paulsen G, Cumming KT, Holden G, Hallén J, Rønnestad BR, Sveen O et al (2014) Vitamin C and E supplementation hampers cellular adaptation to endurance training in humans: a doubleblind, randomised, controlled trial. J Physiol 592:1887-1901. doi:10.1113/jphysiol.2013.267419 
40. Xie Z, Kometiani P, Liu J, Li J, Shapiro JI, Askari A (1999) Intracellular reactive oxygen species mediate the linkage of $\mathrm{Na}^{+} /$ $\mathrm{K}^{+}$-ATPase to hypertrophy and its marker genes in cardiac myocytes. J Biol Chem 274:19323-19328

41. Wray DW, Uberoi A, Lawrenson L, Bailey DM, Richardson RS (2009) Oral antioxidants and cardiovascular health in the exercise-trained and untrained elderly: a radically different outcome. Clin Sci (Lond) 116:433-441. doi:10.1042/CS20080337

42. Gomez-Cabrera MC, Salvador-Pascual A, Cabo H, Ferrando B, Viña J (2015) Redox modulation of mitochondriogenesis in exercise. Does antioxidant supplementation blunt the benefits of exercise training? Free Radic Biol Med 86:37-46. doi:10.1016/j. freeradbiomed.2015.04.006

43. Ristow M, Zarse K, Oberbach A, Klöting N, Birringer M, Kiehntopf $\mathrm{M}$ et al (2009) Antioxidants prevent health-promoting effects of physical exercise in humans. Proc Natl Acad Sci USA 106:8665-8670. doi:10.1073/pnas.0903485106

44. Margaritelis NV, Theodorou AA, Paschalis V, Veskoukis AS, Dipla K, Zafeiridis A et al (2017) Adaptations to endurance training depend on exercise-induced oxidative stress: exploiting redox interindividual variability. Acta Physiol (Oxf). doi:10. 1111/apha. 12898

45. Margaritelis NV, Kyparos A, Paschalis V, Theodorou AA, Panayiotou G, Zafeiridis A et al (2014) Reductive stress after exercise: the issue of redox individuality. Redox Biol 2:520-528. doi:10.1016/j.redox.2014.02.003

46. Stagos D, Goutzourelas N, Ntontou AM, Kafantaris I, Deli CK, Poulios A et al (2015) Assessment of eccentric exercise-induced oxidative stress using oxidation-reduction potential markers. Oxid Med Cell Longev 2015:204615. doi:10.1155/2015/204615

47. Pesta D, Roden M (2017) The Janus head of oxidative stress in metabolic diseases and during physical exercise. Curr Diabetes Rep 17:41. doi:10.1007/s11892-017-0867-2

48. Parker L, Shaw CS, Stepto NK, Levinger I (2017) Exercise and glycemic control: focus on redox homeostasis and redox-sensitive protein signaling. Front Endocrinol (Lausanne) 8:87. doi:10. 3389/fendo.2017.00087

49. Child R, Brown S, Day S, Donnelly A, Roper H, Saxton J (1999) Changes in indices of antioxidant status, lipid peroxidation and inflammation in human skeletal muscle after eccentric muscle actions. Clin Sci (Lond) 96:105-115

50. American Diabetes A (2015) (2) Classification and diagnosis of diabetes. Diabetes Care 38:S8-S16. doi:10.2337/dc15-S005

51. Philippe M, Gatterer H, Eder EM, Dzien A, Somavilla M, Melmer A et al (2017) The effects of 3 weeks of uphill and downhill walking on blood lipids and glucose metabolism in pre-diabetic men: a pilot study. J Sports Sci Med 16:35-43

52. Smutok MA, Reece C, Kokkinos PF, Farmer CM, Dawson PK, DeVane J et al (1994) Effects of exercise training modality on glucose tolerance in men with abnormal glucose regulation. Int $\mathbf{J}$ Sports Med 15:283-289. doi:10.1055/s-2007-1021061

53. Borg G (1970) Perceived exertion as an indicator of somatic stress. Scand J Rehabil Med 2:92-98
54. Coratella G, Bertinato L (2015) Isoload vs isokinetic eccentric exercise: a direct comparison of exercise-induced muscle damage and repeated bout effect. Sport Sci Health 11:87-96

55. Takuro M, Katsunori T, Mariko M, Naoya Y, Tomoshi T, Keitaro $M$ et al (2014) Video-assisted thoracic surgery attenuates perioperative oxidative stress response in lung cancer patients: a preliminary study. Acta Med Nagasaki 59:19-25

56. Pialoux V, Mounier R, Ponsot E, Rock E, Mazur A, Dufour S et al (2006) Effects of exercise and training in hypoxia on antioxidant/pro-oxidant balance. Eur J Clin Nutr 60:1345-1354. doi:10.1038/sj.ejcn.1602462

57. Askew EW (2002) Work at high altitude and oxidative stress: antioxidant nutrients. Toxicology 180:107-119

58. Wozniak A, Drewa G, Chesy G, Rakowski A, Rozwodowska M, Olszewska D (2001) Effect of altitude training on the peroxidation and antioxidant enzymes in sportsmen. Med Sci Sports Exerc 33:1109-1113

59. Clarkson PM, Thompson HS (2000) Antioxidants: what role do they play in physical activity and health? Am J Clin Nutr 72:637S-646S

60. Robertson JD, Maughan RJ, Duthie GG, Morrice PC (1991) Increased blood antioxidant systems of runners in response to training load. Clin Sci (Lond) 80:611-618

61. Yagi K (1992) Lipid peroxides and exercise. Med Sport Sci $37: 40-42$

62. Dillard CJ, Litov RE, Savin WM, Dumelin EE, Tappel AL (1978) Effects of exercise, vitamin E, and ozone on pulmonary function and lipid peroxidation. J Appl Physiol Respir Environ Exerc Physiol 45:927-932

63. Margaritis I, Tessier F, Richard MJ, Marconnet P (1997) No evidence of oxidative stress after a triathlon race in highly trained competitors. Int J Sports Med 18:186-190. doi:10.1055/s-2007972617

64. Dernbach AR, Sherman WM, Simonsen JC, Flowers KM, Lamb DR (1993) No evidence of oxidant stress during high-intensity rowing training. J Appl Physiol 74:2140-2145

65. Gutwenger I, Hofer G, Gutwenger AK, Sandri M, Wiedermann CJ (2015) Pilot study on the effects of a 2-week hiking vacation at moderate versus low altitude on plasma parameters of carbohydrate and lipid metabolism in patients with metabolic syndrome. BMC Res Notes 8:103. doi:10.1186/s13104-015-1066-3

66. Chen SM, Lin HY, Kuo CH (2013) Altitude training improves glycemic control. Chin J Physiol 56:193-198. doi:10.4077/CJP. 2013.BAB 130

67. Lee WC, Chen JJ, Ho HY, Hou CW, Liang MP, Shen YW et al (2003) Short-term altitude mountain living improves glycemic control. High Alt Med Biol 4:81-91. doi:10.1089/ 152702903321489013

68. Nimse SB, Pal D (2015) Free radicals, natural antioxidants, and their reaction mechanisms. RSC Adv 5:27986-28006. doi:10. 1039/c4ra13315c 